\title{
Turismo de Base Comunitária: possibilidades de empoderamento da Comunidade Serra Negra, Almas (TO)
}

\section{Tourism Community Based: empowerment possibilities of Serra Negra Community, Almas (TO, Brazil)}

\author{
Alice Fátima Amaral, Ana Claudia Macedo Sampaio, \\ Noeci Carvalho Messias, Valdirene dos Santos Gomes de Jesus
}

\section{RESUMO}

O objetivo deste trabalho consiste em apresentar um projeto de pesquisa e extensão, de Turismo com base em sistema cooperativo, que agrega o turismo, a agricultura familiar e a participação comunitária e que vem sendo desenvolvido, na Comunidade Serra Negra, no município de Almas (TO). A região em questão se caracteriza pela presença de inúmeras cachoeiras, cânions, serras, nascentes de rios, formações rochosas, além do patrimônio cultural das comunidades. Este rico patrimônio cultural e natural de potencial turístico da comunidade vem sendo explorado por algumas empresas e grupos de outros estados de maneira incipiente e desordenada, excluindo a comunidade do processo, gerando resíduos sólidos e explorando os recursos sem a devida consciência socioambiental e sociocultural exigida pelo Turismo. É neste contexto que emerge a pesquisa-ação que está sendo realizada em parceria com o Ruraltins, a Associação dos Mini Produtores Rurais da Comunidade Serra Negra e a UFT/Câmpus de Arraias/Curso de Turismo Patrimonial e Socioambiental, com objetivo de desenvolver e implantar um modelo de turismo que estimule a gestão responsável de empreendimentos e serviços. Nesse sentido, o corpo técnico de professores e estudantes do Curso de Turismo Patrimonial e Socioambiental vem realizando orientações, assessoria e ações técnicas e cientifica junto à Comunidade Serra Negra quanto à organização do Turismo em seu território, na organização da segurança dos atrativos, na formatação de roteiros, e na preservação ambiental e cultural. Esta parceria busca conciliar as orientações técnicas/científicas com 0 saber tradicional, com a perspectiva de empoderamento da comunidade como gestora do processo de desenvolvimento do turismo em seu território e explorando outros ganhos que superam a questão financeira, como a qualidade de vida, valorização cultural e emancipação da comunidade.

PALAVRAS-CHAVE: Comunidade Serra Negra; Turismo de Base Comunitária; Empoderamento. 


\section{ABSTRACT}

The objective of this study is to present a research and an extension project of tourism based on a cooperative system, which combines tourism, family farming and community participation which have been developed in the Serra Negra Community, in the municipality of Almas (TO, Brazil). The region in question is characterized by the presence of numerous waterfalls, canyons, mountains, sources of rivers, rock formations, beyond the cultural heritage of the communities. This rich cultural and natural heritage of tourism potential of the community has been exploited by some companies and groups from other states in an incipient and disorderly manner, excluding the community from the process, generating solid waste and exploiting resources without proper environmental and socio-cultural awareness required by the Tourism. It is in this context that emerges the action research that is being conducted in partnership with the Ruraltins, the Association of Mini Community Farmers of Serra Negra and the UFT / Arraias Campus / Environmental and Heritage Tourism course, aiming to develop and implement a tourism model that encourages the responsible management of projects and services. In this sense, the staff of professors and students of Environmental and Heritage Tourism course has been carrying out guidance, advice and technical and scientific actions to the Serra Negra Community with respect to the Tourism organization in its territory in the attractive security organization, formatting routes, and in the environmental and cultural preservation. This partnership seeks to reconcile the technical / scientific guidance with the traditional knowledge with the community empowerment perspective as a manager of the tourism development process in its territory and exploring other gains that outweigh the financial issue, such as the quality of life, cultural appreciation an emancipation of the community.

KEYWORDS: Serra Negra Community; Community-Based Tourism; Empowerment.

\section{Introdução}

O município de Almas está localizado na região sudeste do estado do Tocantins. A história da cidade de Almas remonta ao século XVIII com a chegada dos primeiros moradores, vindos em busca de ouro. Com o fim do ciclo do ouro, a economia da cidade foi retomada com o desenvolvimento da agropecuária na região. De acordo com o censo demográfico (IBGE, 2010), a população é de 7.586 pessoas.

Almas tem muitas belezas naturais com enorme potencial para 0 ecoturismo. Na região da Serra Negra, com altitude média de 550 metros, se concentram a maioria dos atrativos do referido município. No local, a natureza está em ótimo estado de conservação, com amplos horizontes de veredas, lagoas, córregos, cânions, cachoeiras e formações rochosas, como - Arco do Sol. A Serra Negra fica a $60 \mathrm{~km}$ do Centro da cidade de Almas.

Os variados atrativos naturais (Figura 1), ainda pouco conhecidos, se destacam pela exuberante beleza, como o Vale do Encantado, onde é 
possível ter a visão de quatro quedas d'água simultâneas, com mais de $70 \mathrm{~m}$ de altura. Há ainda o Cânion do Chupé, que fica a 700m de altitude (o ponto mais alto da região), com o Córrego Chupé, que corta a serra, deslizando em cascata sobre paredões de rochas negras, de uma altura de $250 \mathrm{~m}$. Ao longo do percurso, vão se formando poços de água cristalina. Ainda na região, fica a Serra do Gambá, onde as águas nascem no alto da serra e deslizam em cascata pelos paredões de pedra, e ao longo do percurso vão formando poços de água cristalina.

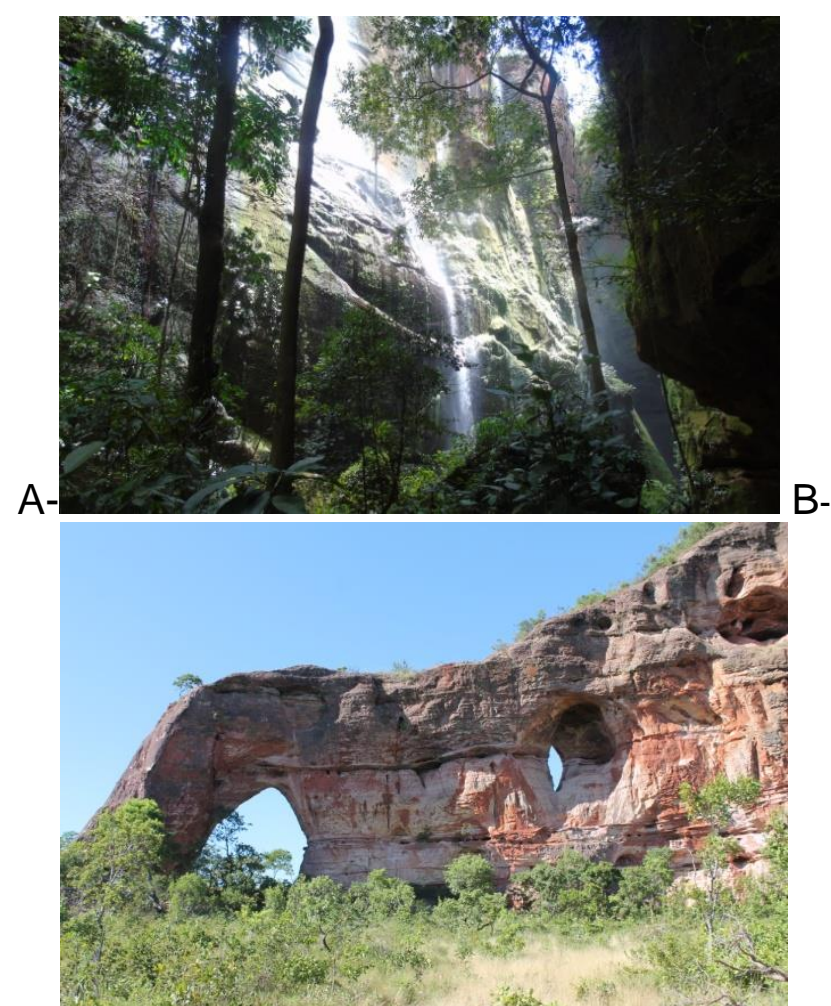

Figura 1: Imagens de atrativos naturais na Comunidade Serra Negra no Município de Almas (TO). A - Cânion Encantado; B - Arco do Sol.

Figure 1: Images of natural attractions in Serra Negra Community in the Municipality of Almas (TO, Brazil). A - Cânion Encantado; B - Arco do Sol.

Outro aspecto significativo da região de Almas é o modo de vida local, marcado por uma identidade rural expressada pelas festas populares e religiosas como a do Divino Espírito Santo, com giros de folias, catira, suça, encontro de foliões, procissões, manifestações estas particulares dos povos campesinos. Diante dos atrativos e potenciais em questão, configura-se um leque de opções de lazer com as possibilidades de prática de diversas atividades que podem envolver o religioso, a aventura, a agricultura familiar, o rural, o cultural, entre outros.

Nesta região, o Instituto de Desenvolvimento Rural do Tocantins (Ruraltins) realiza a assessoria técnica aos campesinos e acompanhamento no fortalecimento de atividades não agrícolas, visando o crescimento da agricultura familiar. Em 2015, o órgão apresentou um significativo número de atendimentos voltados para atividades de turismo rural, revelando o crescente interesse no fomento do turismo como atividade complementar à agricultura por parte dos produtores com respaldo técnico. 
Assim, o Ruraltins mostra-se favorável ao turismo, pela capacidade do mesmo de gerar postos de trabalho, renda, preservação e recuperação cultural e ambiental e a dinamização de economias existentes, tais como a agricultura, a pecuária, a agroindústria, a agroecologia e valorização dos recursos hídricos e artesanato.

Os atrativos, potenciais turísticos da região da Serra Negra, ainda pouco conhecidos, vem sendo explorados de forma predatória, por alguns grupos e empresas especializadas em modalidades de aventura que buscam apenas cenários naturais desconectados dos grupos sociais que aí vivem. Em meio ao fato de que os atrativos naturais, presentes em grande parte dos estabelecimentos são bastante utilizados sem as devidas medidas preservacionistas. Trabalhar os potenciais turísticos identificados na região envolve medidas de levantamentos, mapeamentos, pesquisas, e acima de tudo, o desenvolvimento conjunto das comunidades em torno da capacidade coletiva de refletir e gerir os possíveis projetos turísticos que lá se estabelecerão.

É neste contexto que se insere o projeto de apoio técnico e científico à Comunidade Serra Negra, visando o desenvolvimento do Turismo em seu território como alternativa de complementação a produção agrícola. $O$ projeto em questão trabalha com a possibilidade de agregar valor as suas atividades, tanto para o turismo, como para a agricultura familiar, a partir da conjunção de ambos.

\section{Turismo de Base Comunitária: perspectivas de valorização dos modos de vida das comunidades tradicionais}

Há algum tempo, o Turismo vem sendo entendido como uma nova possibilidade de se promover o desenvolvimento sustentável por meio de diferentes caminhos que busquem estratégias de futuro que conciliem os imperativos do desenvolvimento social, cultural e econômico. Assim, ele se apresenta como uma ferramenta auxiliar no fortalecimento da agricultura familiar, abrindo novas possibilidades de comercialização direta com consumidor final e com cadeia produtiva, favorecendo a consolidação de uma marca/produtos das unidades agrícolas e a diversificação produtiva das propriedades, além de auxiliar na promoção e reconhecimento dos modos de vida, dos saberes e fazeres das comunidades do campo.

O turismo, nesse contexto, favorece a diversificação das atividades do campo, incentiva e promove a permanência dos produtores no campo e ainda fortalece a agricultura familiar, promovendo o desenvolvimento em vários níveis com impactos diretos, indiretos e induzidos. Pode favorecer a geração de emprego e renda para a comunidade, além de colaborar com a preservação e valorização do meio ambiente e da cultura associada à vida no campo.

Alguns autores (CANDIOTTO 2007, RODRIGUES 2000, ALBURQUEQUE 2001, CAVACO 2001), discutem, há algum tempo, a participação do turismo no desenvolvimento da agricultura familiar como ferramenta auxiliar. O fortalecimento de uma marca e a distribuição dos 
produtos, diretamente ao consumidor, são pontos a serem favorecidos pela atividade turística voltada ao âmbito rural, além de opção a tão necessária diversificação dos produtos. No entanto, o turismo também pode ser beneficiado pela agricultura, na formatação de um destino turístico mais afinado com a identidade local, contemplando o social, econômico, cultural e ambiental no desenvolvimento regional. Dessa maneira, torna-se necessária à verificação das variadas possibilidades do turismo no favorecimento a agricultura familiar e vice-versa.

Conforme Cavaco (2001, p. 26),

o turismo é uma atividade reconhecida como promotora do desenvolvimento em vários níveis com impactos diretos, indiretos e induzidos. Assim pode ser definido como: Atividade transversal, global, de fronteiras fluídas, interfere nos tecidos econômicos e sociais, nas dinâmicas demográficas e do emprego, no patrimônio natural e cultural, nos comportamentos das populações e na ocupação, ordenamento e funcionamento dos territórios. Anima o mercado dos produtos e serviços locais, viabilizando microempresas de ramos diversos.

Por esse caráter múltiplo e dinamizador do turismo, a implantação de projetos na área rural é considerada uma alternativa aos problemas da agricultura familiar. A capacidade de gerar emprego e renda, promover a criação de infraestruturas e trocas entre o meio rural e urbano, leva o turismo a desempenhar um papel significativo no desenvolvimento de zonas desfavorecidas (ALBUQUERQUE, 2001).

Nessa mesma linha de pensamento Oliveira (2001) também salienta que o turismo possibilita o contato direto entre produtor e consumidor final na venda dos produtos, melhorando os preços na transação e ainda agregando valor.

\begin{abstract}
Assim, esse tipo de turismo pode ser entendido como instrumento de interiorização do turismo, difusão de conhecimentos e técnicas agrárias diversificação dos pólos turísticos, diminuição do êxodo rural, melhoria da qualidade de vida da população rural, promoção de intercâmbio cultural, sensibilização quanto aos recursos naturais e ainda promover o reencontro com as origens (OLIVEIRA, 2001, p. 279).
\end{abstract}

Todavia, o autor ressalta que o turismo não pode ser a única atividade da propriedade, mas uma fonte de renda complementar as comunidades tradicionais.

Para Morais et al. (2001) a solução para os problemas dos pequenos produtores passa pela melhoria do campo com o incremento na renda a partir da diversificação produtiva e/ou pluriatividade, podendo se beneficiar com a atual necessidade de fuga dos ambientes urbanos, buscando lugares junto à natureza; possibilitando novas iniciativas que contribuam não 
somente para a sobrevivência dos agricultores, mas também para os visitantes. Assim:

Se o deslocamento territorial, por si só, tem implicações profundas na construção da personalidade, a prática turística incorporada ao consumo estético das paisagens pode produzir não somente novas identidades e estilos de vida, mas também atitudes e ações sociais. È o caso em que os turistas impõem, pela necessidade do consumo da natureza, uma relação mais equilibrada com 0 meio ambiente (SERRANO et al., 2000, p. 134).

Em alguns países da Europa, o turismo desenvolvido nas áreas rurais encontra-se em um estágio bem mais avançado em relação a pesquisas acerca dos desdobramentos da atividade no meio. Em Portugal, por exemplo, existem políticas públicas integrada a programas de desenvolvimento territorial, voltadas para regiões despovoadas. A França, que é considerada a pioneira na discussão, publicou um Manifesto em 1972, incentivando entre outras a cooperação de base local, preservação da autenticidade rural e comercialização de produtos específicos com uma imagem de marca. Porém, ressalta-se que tratam de realidades diferentes.

Segundo Magro (2002), o turismo praticado nas áreas rurais pode possibilitar a geração de emprego e renda, que busca garantir a melhoria de qualidade de vida dos atores com a diversificação produtiva das unidades, tendo mais chances de sustentabilidade por atrair um pequeno número de turistas. Tais aspectos são identificados como contrários ao turismo de massa, segundo Ruschmann (1997), que foram formados por um processo histórico que coincide com a crise ambiental, econômica e ideológica que leva à fuga do ambiente urbano.

Assim, para Silveira (2006) o turismo no espaço rural, pode ser visto como uma forma alternativa e economicamente como uma opção de exploração com fins turísticos, dos espaços que possuam características rurais ou naturais. No entanto, além do aspecto econômico, "o turismo rural, ou ecoturismo, é hoje contemplado como uma ferramenta estratégica na conservação do meio ambiente e na preservação das culturas locais, regenerando florestas, ermos e identidades" (TALAVERA, 2000, p. 152).

O turismo rural é uma opção para sobrevivência, do modo de vida rural do agricultor familiar, incorporando valor às atividades produtivas. Esse tipo de turismo valoriza o patrimônio cultural e natural, aprimora a infraestrutura, permite a qualificação da mão-de-obra, apoiando a formação profissional, desenvolve as pequenas e médias indústrias (artesanatos e produtos alimentícios), incentiva a valorização do meio natural e comercialização dos produtos regionais (ZDEPSKI, 2001).

Nesse contexto, o associativismo, que se transformou há algum tempo em uma alternativa para os pequenos produtores agrícolas, traz a ideia de participação e coesão como fundamento a ser utilizado no fomento da atividade turística nas regiões rurais, onde há inúmeros fatores limitantes 
ao desenvolvimento como um todo. $O$ associativismo agrícola apresenta condições, em muitos lugares, de transformação do meio social e econômico em que está inserido, com o incentivo de alcançar soluções desejadas a problemas impostos ao agricultor familiar.

O tema em pauta torna-se oportuno diante da busca por condições de fomento do turismo na região de Almas (TO), baseado principalmente no tradicionalismo rural da mesma, com estabelecimentos e infraestrutura explorando esse caráter.

Reconhecer a complexidade no desenvolvimento da atividade turística, integrando a vocação local e os elementos culturais, bem como a participação dos atores envolvidos, permite construir um diferencial que possibilita um posicionamento estratégico no mercado, agregando, também, valores aos produtos a serem oferecidos e promovendo, talvez, o desenvolvimento sustentável. Pois, como poderá Moesch (2002, p. 130)

o sujeito do turismo não é só economicus e político, mas subjetivo, afetivo e lúdico, dimensões essenciais de sua existência, ele é multidimensional, não de maneira harmônica, complementar, realizada, passível de classificação, mas no conflito, na contradição, no jogo de papéis de máscaras que o turismo possa lhe estabelecer.

Portanto, deve-se reconhecer a importância do turismo praticado no espaço rural, não somente como fato de diversificação de atividades, mas também um elemento capaz de melhorar a condição de vida da família, bem como sua autoestima (VIEIRA, 2005).

No caso deste turismo, os aspectos culturais estão intrinsecamente ligados nos produtos oferecidos aos visitantes. Assim, nesse contexto, o interesse pelo patrimônio cultural, antes circunscrito a uma minoria, tende a tornar-se um eixo estruturante da memória coletiva e, simultaneamente, um produto de consumo turístico cada vez mais popular (FONSECA, 2001). O Ruralismo vendido pela atividade é revestido da vivência, identidade e memória dos indivíduos do campo, mas também são compartilhados com os envolvidos no processo. No entanto, não com a mesma intensidade, onde os sentimentos de pertença, origem, renovação, sacralizados pelo grupo são codificados pelos intermediários da viagem como mostras de autenticidade do lugar, despertando no consumidor 0 bucolismo a beira do desaparecimento.

\footnotetext{
A noção de patrimônio como recurso para o desenvolvimento é uma construção recente e está intimamente associada à especificidade que lhe permite fazer do espaço onde se localiza um lugar diferente de todos os outros, transformando-o numa atração turística que combina elementos tão diferenciados, ensejando a experiência da descoberta, de exotismo, de autorrealização e de evasão do cotidiano (FONSECA, 2001, p. 48).
} 
Segundo Halbwachs (2004, p. 139), os elementos culturais que se transformam em "produtos turísticos" e especialmente no caráter singular do local alteram irreversivelmente os espaços e as relações da comunidade com o mesmo:

O lugar ocupado por um grupo não é como um quadro negro sobre o qual escrevemos, depois apagamos os números e figuras [...]. Todavia, o lugar recebeu a marca do grupo, e vice-versa[...]. Então, todas as ações do grupo podem se traduzir em termos espaciais, e o lugar ocupado por ele é somente a reunião de todos os termos. Cada aspecto, cada detalhe desse lugar em si mesmo tem um sentido que é inteligível apenas para os membros do grupo [...]. Certamente, os acontecimentos excepcionais sempre causam uma mudança nas relações do grupo com o lugar... A partir desse momento, não será mais exatamente o mesmo grupo, nem a mesma memória coletiva; mas, ao mesmo tempo, o ambiente material não mais será o mesmo.

O turismo então provocaria, no espaço rural, interferências profundas e irremediáveis em alguns casos. Porém, alguns autores como Yazigi (2001) e Pires (2010) afirmam que essas interferências, nos aspectos culturais, fazem parte do processo histórico local, ou seja, sempre irá ocorrer algum tipo de mudança provocada por atores externos. Isso torna tênue à divisão entre as consequências negativas e positivas do turismo aplicadas nesses espaços.

Por essas razões, as dinâmicas culturais, que influenciam no desenvolvimento das atividades econômicas em geral, resistem ou sofrem resistências e devem ser consideradas, em todas as suas nuances, no planejamento do turismo, buscando a inserção social, pois, trata-se de uma reinvenção do rural para o consumo que pode gerar benefícios ou malefícios, a comunidade envolvida. Assim, "a ideia de que a valorização do patrimônio, pela via do turismo, constitui, só por si, a solução para o problema das áreas rurais em declínio, é um risco a evitar a todo custo, sob pena de o turismo não passar de uma miragem que rapidamente se desfaz"' (FONSECA, 2001, p. 77).

Pires (2010) argumenta que a dinâmica cultural gera mudanças constantes por meio da transmissão de conhecimento e comportamento entre as gerações, logo, a sociedade muda em resposta ao ambiente e à tecnologia e, não diferentemente, as diversas culturas se modificam com tempo. A autora destaca ainda que o Turismo aparece como elemento que dialoga com as transformações socioculturais, talvez, até indutor, mas dependente e interligado com inúmeros outros elementos possibilitadores de mudanças, logo atribuir-lhe culpa unicamente pelas consequências negativas e considerar a preservação cultural como algo estanque nos planejamentos turísticos ou estudos também desvirtua seu entendimento.

O papel que cabe ao turismo, dentro dessa perspectiva, é o de respeitar a multiplicidade cultural, sendo a existência de diferentes grupos 
sociais dentro de uma mesma sociedade, bem como seus modos de vida e códigos sociais. Contemplar o conceito de comunidade heterogênea no turismo requer ir além de fomentar a gestão participativa, necessita perceber a influência das especificidades sociais, alimentar o pertencimento dos grupos e ainda promover o exercício da cidadania e o respeito à memória dos envolvidos.

Pensar a sociedade formada por grupos sociais diferentes que convivem dentro de um mesmo espaço, ora mudando-o ou ora sendo mudado, somados a interesses dispares, incompatibiliza-se com o pano de fundo da homogeneidade social delineado em alguns estudos e pesquisas que tratam das questões comunitárias que deveriam buscar respostas de como o turismo influencia e é influenciado, contrariando a ênfase dada aos interesses econômicos dos aspectos culturais na promoção do destino. (FINE, 2006).

A cultura, em grande parte dos estudos do turismo reverte-se da face mercadológica, atendendo a demanda comercial, utilizada como subproduto da atividade turística e como fator de atratividade ou singularidade do destino a ser visitado, ou elemento agregador de valor ao produto turístico. $\mathrm{E}$ os conflitos e outras interações entre diferentes grupos são desconsiderados nas análises e planejamento do turismo, sendo essas algumas das consequências no processo de gestão ou estabelecimento do mesmo em qualquer comunidade. (PIRES, 2010).

As relações socioculturais, frente ao estabelecimento do turismo, podem impor limitações e distorções ao processo e, às possibilidades de trocas da interação entre turistas e diferentes grupos sociais de uma localidade desperdiçadas em prol do econômico. A coisificação da cultura restringe a visibilidade do que pode ser conseguido a partir do diálogo entre ambos, ao invés da relação de clientelismo imposta as comunidades envolvidas na exploração da atividade turística.

\section{Apoio técnico e científico à Comunidade Serra Negra: possibilidades de turismo e empoderamento}

O Projeto Turismo na Comunidade Serra Negra firmado entre o Curso de Turismo Patrimonial e Socioambiental da Universidade Federal do Tocantins/Câmpus Arraias, o Ruraltins e a Associação dos Mini Produtores Rurais da Serra Negra (AMIPRUSEN), emerge focado na conjunção do turismo e da agricultura familiar, ambos agregando valor a suas atividades.

Esta parceria contempla o turismo não só como agente influenciador, mas também influenciável à luz das relações de associativismo. Ao longo da história da agricultura no Brasil, o associativismo foi à alternativa de enfrentamento encontrada ao cenário de exclusão dos pequenos produtores que não se enquadram nas novas exigências globais, contudo, tal configuração também favorece o desenvolvimento do turismo.

O corpo técnico de professores e estudantes do Curso de Turismo, percebeu ser urgente o fortalecimento da comunidade no enfrentamento dos problemas inerentes e nesse contexto. A troca de informações entre as diversas formas de conhecimento se torna o pilar desta parceria que busca 
conciliar as orientações técnicas/científicas com o saber tradicional, empoderando a comunidade como a gestora do processo de desenvolvimento do turismo em seu território e explorando outros ganhos que superam a questão financeira, como a qualidade de vida, valorização cultural e emancipação da comunidade.

Assim, o projeto compreende a complexidade intrínseca que envolve uma proposta de desenvolvimento que agrega o turismo, a agricultura familiar e a participação comunitária e, por isso, entende que somente é possível tal empreitada em uma construção coletiva com a parceria e apoio do Ruraltins, da Associação da Comunidade Serra Negra e da UFT/Câmpus de Arraias/Curso de Turismo Patrimonial e Socioambiental. Para tanto, desenvolver e implantar um modelo de turismo com base em sistema cooperativo que estimula a gestão responsável de empreendimentos e serviços é uma necessidade basilar.

$\mathrm{Na}$ perspectiva de consecução dos objetivos desse projeto, os partícipes se comprometeram em promover ampla e intensa colaboração técnica, mediante o intercâmbio de experiências, informações e apoio técnico e científico. Nesse sentido, as atribuições do Curso de Turismo Patrimonial e Socioambiental Universidade Federal do Tocantins-Câmpus Arraias, consistem em prestar orientações técnicas e cientifica a Comunidade Serra Negra quanto à organização do turismo em seu território. Auxiliar no cumprimento das metas estabelecidas em parceria com a Comunidade Serra Negra e o Ruraltins; assessorar a comunidade na organização da segurança dos atrativos, na formatação de roteiros, no desenvolvimento de ações voltadas para a preservação ambiental e cultural. Cabe, ainda, ao corpo técnico de professores e estudantes do Curso de Turismo garantir o cumprimento das metas como apresentar a associação os resultados das pesquisas, mapeamentos e inventariações realizadas em seu território.

As atribuições do Ruraltins consistem em prestar apoio à equipe técnica do Curso de Turismo Patrimonial e Socioambiental, com acompanhamento sempre que necessário; mobilizar a comunidade para 0 cumprimento das ações definidas em cada encontro; facilitar a intermediação entre a Associação Serra Negra; prestar orientações técnicas e científica quanto ao Mapeamento da Produção Associada do Turismo; e ainda auxiliar na mobilização de outros produtores da região para 0 envolvimento em ações de preservação do meio ambiente e da cultura.

No que diz respeito à Associação Serra Negra compete fornecer informações e dados solicitados para o desenvolvimento do Projeto Turismo na Serra Negra. Auxiliar a equipe técnica do Curso de Turismo Patrimonial e Socioambiental e Ruraltins durante as visitas de campo com acompanhamento, mobilização da comunidade, alojamento e alimentação quando necessário. Participar das reuniões. Realizar as ações definidas como prioritárias pela comunidade para a organização do turismo, segurança dos atrativos, formatação de roteiros, preservação ambiental e cultural, entre outras que julgarem pertinentes. Contemplar coletivamente as recomendações feitas pela equipe técnica. 
Nesta perspectiva, empreendemos algumas metas que buscam na fase inicial a estruturação dos produtos turísticos da comunidade Serra Negra; inventariação dos potenciais turísticos e da produção associada na comunidade, roteirização dos atrativos turísticos. Nesse sentido, realizamos na primeira fase da pesquisa/ação exploratória visitas para adequação das trilhas: condições de segurança e redução dos impactos ambientais; visitas para levantamento dos atrativos turísticos (culturais, fauna e flora); visitas para mapeamento da produção associada e para elaboração coletiva e entrega do roteiro turístico.

\section{Estratégias de promoção da participação e empoderamento da comunidade}

O projeto é uma proposta focada no acompanhamento dos dados e números do turismo, somado a uma metodologia de organização comunitária participativa voltada para o planejamento e monitoramento do turismo, onde o protagonismo social se destaca como garantia de sustentabilidade e como uma potencial ferramenta de desenvolvimento endógeno baseado no capital social local. Entende-se que o resultado a ser alcançado com a participação como processo coletivo transformador é a incorporação de setores marginalizados à vida social, contribuindo assim para uma presença ativa e decisória nos processos da sociedade; renegando-se o enfoque passivo da participação comunitária que apenas recebe benefícios (DEMO, 1994).

Assim, o projeto elege a ação conjunta com a comunidade de Serra Negra, como condição para o desenvolvimento do turismo que perdure e de fato colabore para a solução dos problemas, em contraponto a uma atitude passiva de contemplação via análises acadêmicas, e a inclusão das necessidades e interesses daqueles, direta e indiretamente envolvidos. Nesse sentido, o projeto alia a gestão participativa à realização de pesquisas que permitam monitorar e conhecer o turismo com o intuito de dar condições para a intervenção compartilhada dos atores sociais no desenvolvimento do mesmo.

A metodologia do projeto baseia-se em uma experiência realizada em Grossetto, na Itália, desenvolvido pelo grupo de pesquisadores envolvidos com o Curso de Estudo de Economia do Ambiente e Turismo Sustentável da Universidade de Siena. Esse observatório foi desenvolvido para difundir informações e promover conhecimentos úteis para o desenvolvimento sustentável do turismo. Essa metodologia foi replicada e adaptada para a realidade brasileira pela Universidade de Brasília desde 2008 em diversos municípios com financiamento da Fundação Banco do Brasil que vem investindo anualmente em projetos relacionados com o desenvolvimento de tecnologias sociais.

No caso desse projeto de extensão enfatiza-se especialmente o seu caráter participativo, desenvolvido desde o início do processo e em integração com os estudantes de graduação do curso de Turismo Patrimonial e Socioambiental. Ressalta-se ainda o papel da universidade em retornar a sociedade sua produção dando subsídios para a solução de problemas, inovação e descobertas para o desenvolvimento humano. Sendo 
essa função plenamente atendida pela presente proposta que visa não apenas, colaborar com uma formação integral dos graduandos, mas também ajudar a construir estratégias para um mundo efetivamente sustentável.

Para que uma pesquisa de fato seja participativa, segundo Argumendo (1984), ela deve possuir três dimensões básicas - a produção de conhecimento, a educação e a orientação para a ação - que são interdependentes, pois a produção do conhecimento existe no sentido de orientar a prática, que por sua vez está imbuída da missão de modificar a realidade, mas, simultaneamente, produz também conhecimento que ao mesmo tempo em que adquirir conhecimento, ou seja, o processo educativo equivale a construir e criar uma prática. Essa concepção de participação voltada para educação ação e produção de conhecimento está de alguma maneira presente nas técnicas, diagnósticos e instrumentos recomendados a ação participativa.

Não se trata simplesmente de transferir conteúdos, metodologias e instrumentos de pesquisas a comunidade, parafraseando Freire (2010), mas de criar as possibilidades de reflexão/ação dos atores sociais para que se modifiquem e ampliem suas concepções de realidade, incluindo-se nisso o turismo. Para isso, os processos participativos, imbuídos dessas possibilidades que extrapolam o ganho material dos indivíduos, buscam despertar, e não cercear, a curiosidade dos participantes diante os variados questionamentos em torno de suas problemáticas, justamente, pelo seu potencial de transformação crítica:

Que a estrutura social é obra dos homens e que, se assim for, a sua transformação será também obra dos homens. Isso significa que a sua tarefa fundamental é a de serem sujeitos e não objetos de transformação. Tarefa que lhes exige, durante sua ação sobre a realidade, um aprofundamento de sua tomada de consciência da realidade, objeto de atos contraditórios daqueles que pretendem mantê-la como está e dos que pretendem transformá-la (FREIRE, 2010, p.63).

A ideia de um turismo que incluía a comunidade, tanto na tomada de decisões quanto no controle das atividades turísticas, indiretamente traz a perspectiva de fortalecimento do capital social, cidadania na intenção de promover o empoderamento e emancipação social de seus envolvidos, ainda que não sejam discutidos parte-se da premissa que serão alcançados com a participação. É fundamental entender que "a participação não é algo que possa ser dado, porém, é indispensável abrir espaços para que ela se manifeste" (ARGUMENDO, 1984, p. 197). 


\section{Considerações finais}

A implantação do turismo em conjunto com a agricultura familiar trás inúmeros questionamentos acerca da real possibilidade dessa parceria. Preocupa a migração mesmo que lenta, da atividade agropecuária típica da família para uma situação voltada para a prestação de serviços no meio rural, alterando demasiadamente suas realidades. Porém, o turismo pode ser uma ferramenta que auxilia na diversificação produtiva das pequenas propriedades, gerando renda e emprego, ajudando a fixar a população rural no campo, assim, os benefícios dessa parceria devem-se em grande medida, a forma com que os agricultores familiares colocam em pratica a sua concepção de turismo. Estas situações e condições de certa forma escapam aos preceitos do modelo convencional e pré-concebido de fazer turismo.

O turismo a ser desenvolvido na região da Comunidade Serra Negra requer uma nova concepção de atratividade e colaboração das entidades, envolvidas direta ou indiretamente, com a atividade. O que passa a ser exigido pelo turismo no espaço agrícola, não pode ser encontrado no modelo de desenvolvimento do turismo até então adotado, sendo sua condição de efetividade 0 atrelamento às alternativas/iniciativas de desenvolvimento local. Enfim, a Serra Negra, região com potencial turístico considerável, como exposto no trabalho, apresenta condições de agregar o diferencial ao produto tanto turístico como agrícola. A imagem dos produtos de qualidade, artesanal e exclusivo; canal de venda direta dos produtos, além da venda para os estabelecimentos turísticos por meio dos arranjos produtivos locais, soma vantagens para os produtores rurais, além da atratividade oferecida pelo processo de cultivo da fruta.

\section{Referências}

ALBUQUERQUE, C. Turismo no espaço rural: uma estratégia para o desenvolvimento local. Anais do $3^{\circ}$ Congresso Brasileiro de Turismo Rural Turismo no espaço rural brasileiro. Piracicaba: FEALQ, 2001.

CANDIOTTO, L.Z.P. Turismo rural na agricultura familiar: uma abordagem geográfica do Circuito Italiano de Turismo Rural, município de Colombo PR. Tese (Doutorado em Geografia). Univ. Federal de Santa Catarina, Florianópolis, 2007.

CAVACO, C. O mundo rural português: desafios e futuros. In: RODRIGUES, A. (org.). Turismo Rural. São Paulo: Contexto, 2001.

DEMO, P. Política social, educação e cidadania. Campinas: Papirus, 1994.

FINE, M. et al. Para quem? Pesquisa qualitativa, representações e responsabilidades sociais. In: NORMAM, K; DENZIN, Y; LINCOLN, S. 0 planejamento da pesquisa qualitativa, teorias e abordagens. São Paulo: Artmed, 2006.

FONSECA, M. Para além da pedra e cal: por uma concepção ampla de patrimônio. Revista Tempo Brasileiro, Rio de Janeiro, n. 147, p. 23-27, 2001. 
FREIRE, P. Pedagogia da autonomia: saberes necessários à prática educativa. São Paulo: Paz e Terra, 2010.

HALBWACHS, M. A Memória Coletiva. São Paulo: Centauro, 2004, p. 139.

IBGE. Censo Demográfico de 2010. Fundação Instituto Brasileiro de Geografia e Estatística, dados referentes ao município de Almas Tocantins, fornecidos em meio eletrônico.

MAGRO, T.C. Ambiente natural e turismo em meio rural. In: RIEDL, M.; ALMEIDA, J.A.; VIANA, A.L.B. (Orgs). Turismo rural: tendências e sustentabilidade. Santa Cruz do Sul, SC: EDUNISC, 2002, p. $141-162$.

MOESCH, M. A produção do saber turístico. São Paulo: Contexto, 2002.

OLIVEIRA, C.G.S. Turismo Rural: procedimentos para a implantação e o desenvolvimento dessa atividade em propriedades rurais. Dissertação de Mestrado. São Paulo: ECA/USP, 2001.

PIRES, M. Turismo e Pós-Modernidade. Dissertação de Mestrado. Centro de Excelência. Brasília: CET/UnB, 2010.

RODRIGUES, A. B. Turismo rural no Brasil: ensaio de uma tipologia. In: ALMEIDA, J.A.; RIEDL, M. (Orgs.). Turismo rural: ecologia, lazer e desenvolvimento. Bauru, SP: EDUSC, 2000. p. 51-68.

RUSCHMANN, D. Turismo e planejamento sustentável. Campinas-SP: Papirus, 1997.

SERRANO, C. et al. Olhares contemporâneos sobre o turismo. Campinas-SP: Papirus, 2000.

SILVA, J.G.; VILARINHO, C.; DALE, P.J. Turismo em áreas rurais: suas possibilidades e limitações no Brasil. In: ALMEIDA, J.A.; FROELICH, J.M.; RIEDL, M. (Orgs.). Turismo rural e desenvolvimento sustentável. Campinas, SP: Papirus, 2000. p. 15-62.

SILVEIRA, P. et. al. O turismo e a recriação das agroindústrias rurais tradicionais. Anais do 4 ${ }^{\circ}$ Congresso Internacional sobre o Turismo Rural e desenvolvimento sustentável - Ordenamento, segmentação e regionalização do turismo em áreas rurais. Santa Maria: FACOS-UFSM, 2006.

TALAVERA, A.S. O rural como produto turístico: algo de novo brilha sob o sol? In: SERRANO, C.; BRUHNS, H.T.; LUCHIARI, M.T.D.P. Olhares contemporâneos sobre o turismo. 2. ed. Campinas: Papirus, 2001. Cap. 7, p. 151-170.

VIEIRA, E.M. Políticas Públicas e legislação para o turismo rural. Dissertação de Mestrado. Santa Maria. UFSM, 2005.

YAZIGI, E. A alma do Lugar. São Paulo: Contexto, 2001.

ZDEPSKI, F. Aspectos determinantes da oferta para o desenvolvimento do turismo rural. Anais do $3^{\circ}$ Congresso Brasileiro de Turismo Rural - Turismo no espaço rural brasileiro. Piracicaba: FEALQ, 2001. 
Alice Fátima Amaral: Universidade Federal do Tocantins, Arraias, TO, Brasil.

E-mail: alicefamaral@uft.edu.br

Link para o currículo Lattes: http://lattes.cnpq.br/2992153615005024

Ana Claudia Macedo Sampaio: Universidade Federal do Tocantins, Arraias, TO, Brasil.

E-mail: claudiam_sampaio@hotmail.com

Link para o currículo Lattes: http://lattes.cnpq.br/5950004066824854

Noeci Carvalho Messias: Universidade Federal do Tocantins, Arraias, TO, Brasil.

E-mail: noeci@uft.edu.br

Link para o currículo Lattes: http://lattes.cnpq.br/8189787178162250

Valdirene dos Santos Gomes de Jesus: Universidade Federal do Tocantins, Arraias, TO, Brasil.

E-mail: jesuseval@uft.edu.br

Link para o currículo Lattes: http://lattes.cnpq.br/0485895333028312

Data de submissão: 14 de novembro de 2016

Data de recebimento de correções: 17 de janeiro de 2017

Data do aceite: 17 de janeiro de 2017

Avaliado anonimamente 